\title{
Linking Real-Life Situations with Classroom Assessment: Development of Real-Life Performance-Based Tasks in Business Mathematics
}

\author{
Sheena Mai A. Galman'1, Jennalyn C. Del Rosario² \\ ${ }^{1}$ Faculty of Mathematics, Nueva Ecija University of Science and Technology, Cabanatuan City, Philippines \\ ${ }^{2}$ Eduardo L. Joson Memorial High School, Nueva Ecija, Philippines \\ Email: sheenamaiagalman@gmail.com
}

How to cite this paper: Galman, S.M.A. and Del Rosario, J.C. (2021) Linking RealLife Situations with Classroom Assessment: Development of Real-Life PerformanceBased Tasks in Business Mathematics. Journal of Applied Mathematics and Physics, 9 , 485-502.

https://doi.org/10.4236/jamp.2021.93034

Received: March 1, 2021

Accepted: March 28, 2021

Published: March 31, 2021

Copyright $\odot 2021$ by author(s) and Scientific Research Publishing Inc. This work is licensed under the Creative Commons Attribution International License (CC BY 4.0).

http://creativecommons.org/licenses/by/4.0/

(c) (i) Open Access

\begin{abstract}
This study aimed to develop real-life performance-based tasks in Business Mathematics (RLPBTs) following the ADDIE's model of instructional development. Using the descriptive-developmental research design, the study developed RLPBTS with mathematics experts, mathematics department head, bank manager, mathematics teachers, and students as respondents. The RLPBTs consist of instructional plans. Each instructional plan has these components: Introduction, Learning Competency, Learning Outcome, Task Execution, Scoring Guide, and Generalization. The design and content of the instructional plans were assessed as very good. On the other hand, the design and execution of the Tasks were assessed as favorable. Grade 11 students also agreed that real-life performance-based tasks helped them understand better concepts in business mathematics. They claimed that they enjoyed the tasks because of the inclusion of real-life situations that they simulated. The use of the RLPBTs provides another innovation in the teaching and learning concepts in Business Mathematics.
\end{abstract}

\section{Keywords}

ADDIE Model, Real-Life Performance-Based Tasks, Instructional Plans, Business Mathematics

\section{Introduction}

According to [1], "students find difficulties in learning Mathematics because of the complexity of using symbols and computations. Also, students tend to forget 
previously learned concepts and skills that are necessary for the new skills to be learned. As a result, students lack the needed knowledge and comprehension to advance to the next level of study." Hence, providing activities that encourage learners to create tangible and useful products to be shared with the world is imperative in the learning process. To do this, the teaching and learning process needs more than rote understanding of concepts and performing basic operations and calculations. That is, the whole process calls for on-hand experiences in real-life set-up.

[2] stipulated that learning becomes easy when the lessons are meaningful and student could relate to its significance and importance. In addition, learning becomes more facilitating and effective since real world situations are simulated into assessment activities that may lead to the development of skills which students may apply in their profession.

Business Mathematics is one among the Mathematics courses which have various applications in the real-life setting in commerce, business and banking industries. However, less emphasis is given to this aspect and more is given to understanding concepts and performing the basic computations. Such can be observed during the formative assessment wherein students are usually given a set of activities asking them to identify the concepts being described in the test items or perform the fundamental calculations. The applications can be seen roughly in the sets of problems provided, which should not be the case. Students should experience the actual set-up in the problem by simulating it by way of performance and/or creating something related to it. That is, they may take the role of a professional to facilitate the operations in an industry.

Studies conducted show that assessment tools can improve the performance of students in Mathematics. [3], in his study at the classroom level, teacher assessment practices had significant relationships to classroom performance. Also, cross-level interactions (between student characteristics and teacher practices) suggested that classroom assessment practices might uniquely interact with student characteristics in their role of motivating student effort and performance. The [4] cited evidence that the development of real-life-based mathematics assessments may be a great help in learning improvement. Thus, they have developed a concrete assessment plan called the Problem-Based Learning Design Project (PBL Design project) to answer the needs. [5], in his study, has the same context as the Congress. It was found that in Australia, effective practices in Mathematics through its assessment plans are identified and its positive impact on teaching and learning. In his study, it was found that in Australia, effective practices in Mathematics through its assessment plans are identified and its positive impact on teaching and learning. He added that it must be planned in a broad range to be more helpful, collecting various information before and after a teaching sequence. [6] examined the change process in mathematics in their study. Results are organized around five themes: 1) Situating the change process in the actual contexts where new ideas will be implemented is an effective strategy for helping teachers change their practice; 2) Group discussions can be a useful 
tool for the social construction of new ideas; 3) Staff development personnel can facilitate change by introducing new ideas based on teachers' current levels of interest, understanding, and skill; 4) When teachers' beliefs are incompatible with the intentions of the staff development team and are not challenged, the teachers are likely to either ignore new ideas or inappropriately assimilate them into existing practice; and 5) Time is a significant obstacle to changing classroom practice.

With the benefits of assessment tools proven in General Mathematics, it is feasible to develop the same model of the assessment tool in Business Mathematics, one among the branches of mathematics with many applications in real life. Students find it difficult to apply due to vast terminologies and formulae. Also, the nature of the course requires an understanding of its practical use in the real world through tasks that they would genuinely encounter outside the classroom. As observed during traditional assessment in Business Mathematics, students failed to have appropriate enthusiasm and understanding of the concepts being solved since they could not relate to them. Hence, it was not meaningful. [2] said that learning becomes easy when the lessons are meaningful, and students could relate to their significance and importance. Performance-based tasks clearly show how students execute the skills learned in a simulated situation similar to real life.

This motivated the researchers to conduct a study to develop real-life performance-based tasks in Business Mathematics. That is, to directly link real-life situations in classroom assessment. The researcher intended to develop a performance-based task that is more authentic as it simulated real-life situations in the classroom assessment of learning in Business Mathematics.

\section{Methods}

This study employed the developmental research design. Developmental research is the systematic study of designing, developing instructional programs, processes, and products that must meet internal consistency and effectiveness criteria [7]. This method was the most appropriate to use since its primary goal was to develop a product-an instructional material Grade 11.

The ADDIE (Analysis, Design, Development, Implementation, and Evaluation) of instructional development by [8] was employed in this study, and the GRASP model of [9] was used in the development of the task proper.

The model of development is shown in Figure 1. It shows the step-by-step procedure in the creation of the RLPBTs. In the analysis phase, the available instructional materials and the learning competencies of the Grade 11 mathematics curriculum were reviewed.

The design phase dealt with the format and content of the RLPBTs. The develop phase was the execution of the design phase. During the implementation phase, the RLPBTs were tried out in a Grade 11 mathematics class. The RLPBTs were evaluated during and after the development. The ADDIE Model was cyclic and flexible. This meant that each step could be revisited throughout the process, and revision can be made when called for. 


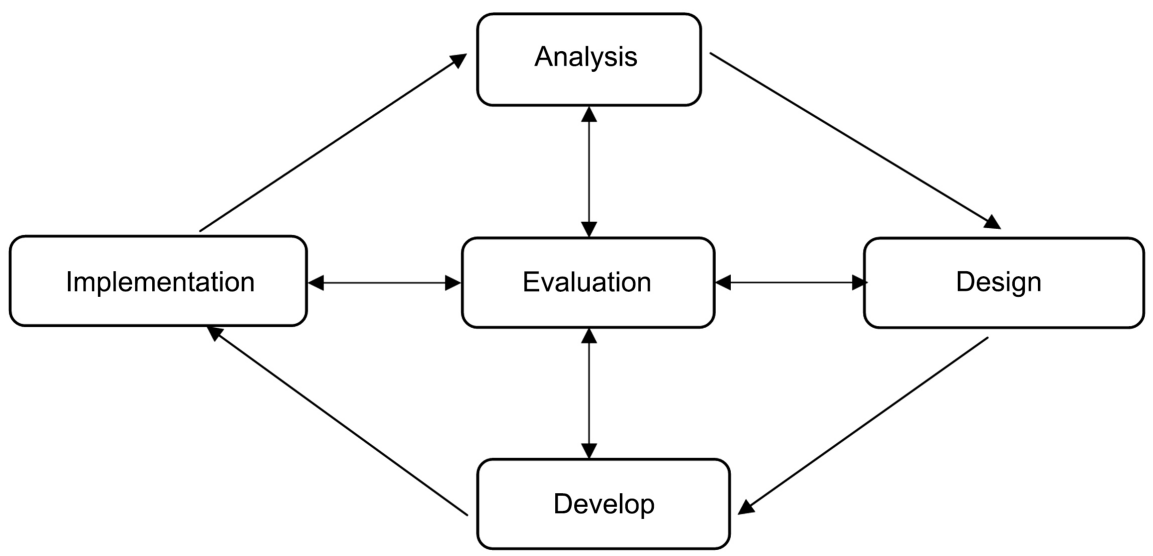

Figure 1. The ADDIE instructional design model.

The samples of the study were nine (9) Mathematics teachers and 38 Grade 11-STEM students. Individual and group compositions of students were created considering the nature of the performance tasks. Thus, the students work individually and/or collaboratively depending upon such nature of the performance tasks.

This study used three instruments, namely: Performance-based Task, Observation Protocol for Grade 11 Mathematics Teachers on the Implementation Phase, and Assessment of the Real-life Performance-based Tasks.

The performance-based tasks consist of eleven performance tasks and have these parts: Introduction, Learning Competency, Learning Outcome, Task proper, Scoring guide, and Generalization.

Some of the performance tasks were done in a group based on Vygotsky's Social Constructivism Approach, while some were done individually. Furthermore, some are process-oriented, while some are product-oriented performance-based tasks.

The conduct of the study had two phases, namely: Development and Assessment. The former comprises analyze, design, develop, implement and evaluation. The latter, is a single-stage phase involving the actual use of the developed instructional material.

Development Phase. The ADDIE model was adopted in the development of the RLPBTs. The five-step procedure was as follows:

Analyze. During the analysis, the researcher examined the learning competency in the Grade 11 mathematics curriculum prescribed by the Department of Education. She selected the lessons where performance-based tasks can be incorporated into business mathematics. She also surveyed teachers about the prevailing conditions in mathematics class about the use of performance-based tasks. A Gantt Chart showing the five-step procedure of development was the output of this phase.

Design. In this stage, the format of the RLPBTs was identified. The RLPBTs had these components: Introduction, Learning Competency, Learning Outcome, Task proper, Scoring, and Generalization. 
Develop. In this stage, the researcher wrote the content of the tasks identified in the design phase. The first draft form was checked by the adviser and a mathematics head. Subsequent revision was done based on their suggestions. Thereafter, the revised form was pilot-tested in ELJMHS for the clarity and readability of the contents, and determination of time allotment. Subsequent revision was done based on the result of the pilot testing.

Implement. In this stage, the developed RLPBTs were carried out or executed in Grade 11 mathematics classes at HCPMSHS.

Evaluate. In this stage, the RLPBTs were subjected to the evaluation.

Assessment Phase. Nine Math teachers assessed the content and execution of the RLPBTs. Twenty students assessed the RLPBTs in terms of their answers in the performance task.

\section{Results}

This section discusses the development and assessment of the real-life performance-based tasks in Business Mathematics.

\subsection{Development of the Real-Life Performance-Based Tasks}

The development of the RLPBTs adopted the ADDIE model of instructional development. It underwent five stages, namely: analysis, design, development, implementation, and evaluation.

\subsubsection{Analysis}

During this stage, the learning competency in the Grade 11 mathematics curriculum as prescribed by the Department of Education (DepEd) was examined.

The lessons in Business Mathematics were selected in which the performance-based tasks can be integrated, such as simple and compound interests, simple and general annuity, stocks and bonds, and business and consumer loans.

Interviews were also conducted among Mathematics teachers of if they used performance-based tasks in Mathematics. The teacher admitted that they did not use performance-based tasks. The teachers follow the learning competency prescribed by the Department of Education in teaching Mathematics, and they supplemented this with readings from other sources like books and the internet. Problems and exercises were given to the students using the traditional method of paper and pencil activities, not using the performance-based tasks.

The findings of the interview provided the researcher inputs in developing RLPBTs. On the other hand, the findings in the analysis stage were used as a benchmark in the succeeding stages of the development.

\subsubsection{Design}

In this stage, the format of the RLPBTs was conceptualized. The RLPBTs had these components: Introduction, Learning Competency, Learning Outcome, Task Proper, Scoring Guide, and Generalization.

The Introduction discusses the overview of the performance-based task in 
Business Mathematics (RLPBTs). It enables the students to envision what they were supposed to do in the task proper. It also asks them how they would do the outcome at the end of the task proper. To make the introduction more focused on the users and interesting to read, a picture was included.

The Learning Competency, the second component of the RLPBTs, states what the students would learn and able to do throughout the task proper.

The Learning Outcome is the expected output of the students at the end of the task.

The Task Proper engages the students to collaborate or perform the performance-based task. In particular, the grasp model was used in task proper. The titles of the different activities are as follows:

Activity 1-Your Interest is my Concern.

Activity 2-How Much and How Long Matters to Me.

Activity 3-Income Explains Everything.

Activity 4-Interest Affects my Payments.

Activity 5-Price Matters.

Activity 6-Monthly Payment Please.

Activity 7-Selfie! Selfie!

Activity 8-Top Gainers or Bottom Three.

Activity 9-Investment in Stocks.

Activity 10-Payment Schedule.

Activity 11-Renewed or New Loan.

The Scoring component of the RLPBTs contains a guide on how the students scored in the task proper. Different assessment tools were used depending on the outputs of the students at the end of the PB Task.

The Generalization component of the RLPBTs summarizes the activity. The students gave their conjectures about the PB task.

The design phase of the development paved the way for the components of the RLPBTs. This is in consonance with the findings of [10]. According to him, the conclusion of the instructional design phase carries with it the creation of an instructional design document that reflects a high-level overview of the entire instructional material. Such overview provides for a set of identified components or parts included in the plan. An example is the provision on the alignment of learning competencies and assessment in the design of the RLPBTs which can be supported by [11] as he emphasized the importance of meaningful alignment of the objectives and assessments.

The same is supported by the findings of [12], as they emphasized that the design of a learning activity is likely to have fixed format for the courses. That is, there is a set of useful guidelines for videos, quizzes, message boards, and polls.

The findings of the present study are the same as the findings of [1] when it comes to considering the salient parts of instructional material. The study of the latter considered several parts such as Introduction, Materials, and Task Proper, among others in the design of the instructional plan. The same is supported by 
the study of [13] when the key design features of study materials were considered in the development. Also, [14] advises that a course unit can consist of an overview, unit objectives, several sections of content divided into sub-sections, interactive questions, a summary, self-assessment questions on the whole unit, and list of additional reading materials.

\subsubsection{Development}

In this stage, the contents of the RLPBTs were written. The template of the RLPBTs presented in the design phase was followed. The eleven RLPBTs developed were the following:

PT Number 1-Simple and Compound Interest.

PT Number 2-Simple and Compound Interest.

PT Number 3-Simple and Compound Interest.

PT Number 4-Simple and General Annuity.

PT Number 5-Simple and General Annuity.

PT Number 6-Simple and General Annuity.

PT Number 7-Simple and General Annuity.

PT Number 8-Stocks and Bonds.

PT Number 9-Stocks and Bonds.

PT Number 10-Business and Consumer Loans.

PT Number 11-Business and Consumer Loans.

In the course of the development of the RLPBTs, the researcher consulted Grade 11 Mathematics teacher and her adviser. The initial draft of the RLPBTs was shown to them, and they commented that the borders of the RLPBTs caused a distraction to the users. They suggested that the borders be removed. The RLPBTs were also tried out among Grade 11 students of school-participant to determine the readability of the content and the time allocation in the execution of the RLPBTs. The first draft of the RLPBTs was revised, and the suggestions of the teachers were incorporated. The second draft of the RLPBTs was again shown to the Mathematics teacher and her adviser for comments and further recommendations. This scenario is supported by the study conducted by [15] and [16]. Based on the former, the development of teaching activities undergoes cyclic evaluation until it can be used for actual practice. Results from teachers' enactments may be used for refinement of the original design to make it more effective. On the other hand, the latter emphasized that the structural design of materials can also have a major impact on learner's comprehension of materials. The design should be appealing to the eyes, for instance, the color should be attractive, illustrations should be clear and relevant to the text and repetition should only be used to show emphasis. Hence, unnecessary details must be omitted.

In sum, the measures undertaken under the develop phase of the study could be supported by [12]. According to them, the development of instructional material must follow a framework, like the present study, in which the design was based. 


\subsubsection{Implementation}

In this stage, the second draft of the RLPBTs was tried among Grade 11 students at another senior high school. The students involved in the implementation were oriented on how the implementation of the RLPBTs would be carried out. Two Grade 11 General Mathematics teachers in the same school served as observers in the implementation of the RLPBTs.

Performance Task 1 (PT 1) was successfully carried out by the researcher and the class. The overview of the performance task was clearly explained by the researcher and clearly understood by the students. The learning competency and learning outcome were simply and clearly stated. In the task proper, the GRASP was easily followed by the students. While performing the situation, it was observed that the students interestingly participated and found enjoyment performing the scenario in the play. In the scoring, all of the criteria were seen in the play, and the groups presented a different level of performance. In generalization, the guide questions were answered correctly. In general, the teacher-observers gave no suggestions in Performance Task 1 in simple and compound interests.

The Performance Task 2 (PT 2) was successfully carried out by the researcher and the class. The overview of the performance task was clearly explained by the researcher and clearly understood by the students. The learning competency and learning outcome were simply and clearly stated. In the task proper, the GRASP was easily followed by the students. While performing the situation, it was observed that the students interestingly answered the given balance sheet and found enjoyment. In the scoring, almost all of the students got a perfect score. In generalization, the guide questions were answered correctly. In general, the teacher-observers gave no suggestions in Performance Task 2 in simple and compound interests.

In Performance Task 3 (PT 3), almost the same comments as in the previous lessons were noted. No recommendations on the components of the RLPBTS were given.

In Performance Task 4 (PT 4), the students found the picture in the introduction interesting because it was a picture taken in an appliance store. The students had an idea of what would happen in the task proper because of the picture. The students clearly understood the learning competency and learning outcome. In the task proper, the GRASP was easily followed by the students because of the picture in the Introduction. While performing the situation, it was observed that the students interestingly participated and found enjoyment performing the scenario in the play. In the scoring, all of the criteria were seen in the play, and the groups presented a different level of performance. In generalization, the guide questions were answered correctly. In general, the teacher-observers gave no suggestions in the Performance Task 4 in a simple and general annuity.

In Performance Task 5 (PT 5), the students were puzzled when the art materials were shown. The picture in the introduction gave them an idea to ask what 
would happen in the task proper. The students had a better understanding of the task when the learning competency and learning outcome were read to them by the researcher. In the task proper, the students enjoyed creating their own leaflet of appliances and suggested if they could give their name of the store and the name of the appliances. Different designs and levels of creativity were shown in the scoring. All entries in the computation of monthly payments, suggested retail price, and cash price were correct. In generalization, the students answered the guide questions immediately because they enjoyed the task proper.

In Performance Task 6 (PT 6), the students found the picture in the introduction interesting because of the car. The students clearly understood the learning competency and learning outcome. In the task proper, one student gave a price of P165,000 for a brand new car which the other students debated; some said that the price was for a pre-owned car. While performing the situation, it was observed that the students answered the task in less than fifteen minutes. The formula was recorded in the calculator, which gave them enough time to answer the proposal. The students gave different suggestions, but most of them chose the higher monthly payments in one year than lower monthly payments in two years. In the scoring, almost all students have a perfect score. In generalization, the guide questions were answered correctly. In general, the teacher-observers gave no suggestions in the Performance Task 6 in the simple and general annuity.

In Performance Task 7 (PT 7), almost the same comments as in the previous PT 5 were noted from the teachers, and students. No recommendations on the components of the RLPBTS were given.

In Performance Task 8 (PT 8), the introduction probed the thinking of the students. The teacher asked them what the task was all about. The picture in the introduction helped them answer their teacher's question. The Learning Competency helped them understand what the task proper was all about. The learning outcome gave them an idea of what they would do in the task proper. In the task proper, after explaining the GRASP and upon receiving the copy of a newspaper, one student asked if the letters in the newspaper could be made larger. It was explained to them that the copy of the newspaper was a duplicate copy, and the standard copy of stocks in the Philippine Stock Exchange written in the newspaper. The students quickly followed the task. In scoring, the teacher-observer suggested that the enumerated companies would be given an additional point. The guide questions gave the students clearer concepts of stocks.

In Performance Task 9 (PT 9), the teacher clearly explained the task's overview and clearly understood by the students. The learning competency and learning outcome were clearly stated. In the task proper, the GRASP was easily followed by the students. While performing the situation, it was observed that the students interestingly answered the given balance sheet and found enjoyment, especially in the broker's commission. The students laughed at each other when they saw some of their seatmates gave commission lower than 100 and asked them if they could gain profit out of that. In response, the student empha- 
sized that she would be considered as a broker by the client because of it. In the scoring, almost all of the students got a perfect score. In generalization, the guide questions were answered correctly. In general, the teacher-observers gave no suggestions in the Performance Task 9 in stocks and bonds.

In Performance Task 10 (PT 10), the students found the picture in the introduction engaging. The students clearly understood the learning competency and learning outcome. In the task proper, Grasp was easily understood by the students. While performing the situation, it was observed that the students frequently asked the question of what would happen at the last payment. The students observed the diminishing outstanding principal and interest. Some students asked why they got an answer of 0.02 at the last outstanding principal. They were confused if that was normal. The teacher explained that they would not attain a perfect zero score, and the decimal point discrepancy in mathematics was considered correct. In the scoring, almost all students have a perfect score. In generalization, the guide questions were answered correctly. In general, the teacher-observers gave no suggestions in the Performance Task 10 in business and consumer loans.

Performance Task 11 (PT 11), almost the same comments as in the previous PT 10, were noted from the teachers and students except in the additional proposal in the task proper. Students gave interesting suggestions if they would choose a renewed loan or a new loan. No recommendations on the components of the RLPBTS were given.

When observed as a whole, the execution of the RLPBTs was successfully carried out. The teacher-observers said that the performance-based tasks were another innovation and strategy in teaching concept and operations on Business Mathematics. The use of the different performance tasks in teaching Business Mathematics proved interesting to students, and enhanced students' maximum participation.

The present study exhibited the implementation phase as a result of the success of the preceding phases. Here, the deductions made out of the responses and reactions of the students imply the appropriateness and workability of the analysis and design phases. This can be supported by the concept of [17] that implementation phase establishes whether the design intention stand up to the test of workability. In addition, he suggested that only if an effective design is accompanied by an effective implementation are desired changes expected to occur in teaching and learning, and therefore the expected outcomes can be observed. It is also in this phase the role of the teacher becomes critical. [18] asserts the importance of the ability of the teachers to recognize salient features of the design are central to the rationale or purpose of the instructional material. Such features should be retained or modified with extreme caution.

\subsubsection{Evaluation}

Each phase was evaluated based on the compliance to every standard and step in each phase. It was shown that the development followed strictly the Gantt Chart 
during the Analysis phase; considering the parts undermined in the Design phase; developing the actual contents based on the design in the Development phase; and considering the guidelines set forth in the Implementation phase. Here, the evaluate phase was carried out in each phase using qualitative analysis. This is supported by the studies conducted by [19] and [20]. The former describes the evaluation phase as crucial in design studies since the results of this phase suggest possible improvements and offer bases for the domain-specific guidelines. The latter suggest using qualitative analysis in order to optimize understanding of the effectiveness of the design under evaluation.

\subsection{Assessment of the Developed RLPBTs}

\subsubsection{Assessment of the Design and Content of the RLPBTs}

The RLPBTs were subjected to the evaluation of two Mathematics experts and a bank manager in Nueva Ecija. The results of their evaluation on the design and content of the RLPBTs were considered in the final draft of the RLPBTs.

Table 1 shows the evaluation of the mathematics expert and bank manager on the RLPBTs. T The data collected using the questionnaire were treated using weighted mean.

Task 1 in simple and compound interest was given a mean rating of 2.93 (Very Good) by the three evaluators $n$ the design. They found six components of this RLPBT simple and clearly written. One evaluator recommends that the picture in the introduction be localized to become more attractive.

Table 1. Summary of evaluation on the design of RLPBTs by mathematics expert and the bank manager.

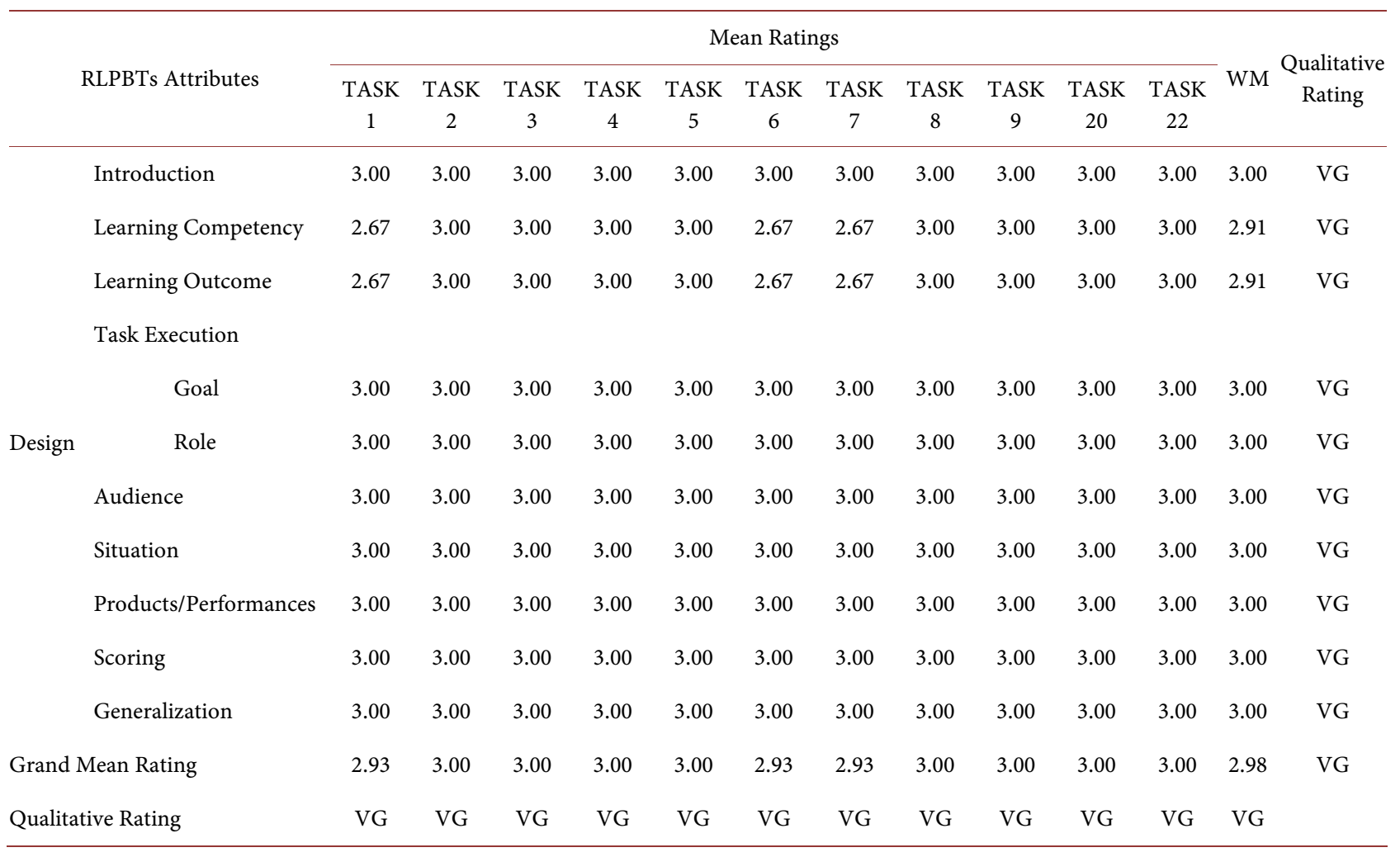


Task 2 was also given a mean rating of 3.0 (Very Good) on design by the three evaluators in simple and compound interest. They did not suggest modifying or revise the RLPBT. They anticipated that students would actively participate in answering the given balance sheet as they imagine that they are in the real world of business offering loans to customers. They said that the design of Task 2 could cater to all types of learners. With these features of Task 2 found by the three evaluators, their judgment on the use of Task 2 on simple and compound interest was favorable.

In Task 3 on simple and compound interest, the grand mean rating on the design was 3.0 (Very Good). Each item on the design was all rated Very Good. No further comments and suggestions were given.

In simple and general annuity Task 4 , the three evaluators gave a grand mean rating of 3.0 (Very Good). One evaluator commented that the task proper was a real situation that the student encountered shortly.

Stocks and Bond, Task 8 was rated with a mean rating of 3.0 (Very Good). Each item on the design was all rated Very Good. No further comments or suggestions were given.

The three evaluators gave a grand mean rating of 3.0 (Very Good) on the design of Task 11. Each item on the design was all rated Very Good. One evaluator suggested that the picture in the introduction b localized. The other two evaluators gave no further comments or suggestions.

Table 2 shows the evaluation of the mathematics expert and bank manager in the content of the RLPBTs.

Table 2. Summary of evaluation on the content of RLPBTs by mathematics expert and the bank manager.

\begin{tabular}{|c|c|c|c|c|c|c|c|c|c|c|c|c|c|}
\hline \multirow{3}{*}{ RLPBTs Attributes } & \multicolumn{11}{|c|}{ Mean Ratings } & \multirow{3}{*}{ WM } & \multirow{3}{*}{$\begin{array}{c}\text { Qualitative } \\
\text { Rating }\end{array}$} \\
\hline & TASK & TASK & TASK & TASK & TASK & TASK & TASK & TASK & TASK & TASK & TASK & & \\
\hline & 1 & 2 & 3 & 4 & 5 & 6 & 7 & 8 & 9 & 20 & 22 & & \\
\hline Introduction & 3.00 & 3.00 & 3.00 & 3.00 & 3.00 & 3.00 & 3.00 & 3.00 & 3.00 & 3.00 & 3.00 & 3 & VG \\
\hline Learning Competency & 2.67 & 3.00 & 3.00 & 3.00 & 2.67 & 2.67 & 3.00 & 3.00 & 3.00 & 3.00 & 3.00 & 2.91 & VG \\
\hline Learning Outcome & 2.67 & 3.00 & 3.00 & 3.00 & 2.67 & 2.67 & 3.00 & 3.00 & 3.00 & 3.00 & 3.00 & 2.91 & VG \\
\hline \multicolumn{14}{|l|}{ Task Execution } \\
\hline Goal & 3.00 & 3.00 & 3.00 & 3.00 & 3.00 & 3.00 & 3.00 & 3.00 & 3.00 & 3.00 & 3.00 & 3 & VG \\
\hline Content & 3.00 & 3.00 & 3.00 & 3.00 & 3.00 & 3.00 & 3.00 & 3.00 & 3.00 & 3.00 & 3.00 & 3 & VG \\
\hline Audience & 3.00 & 3.00 & 3.00 & 3.00 & 3.00 & 3.00 & 3.00 & 3.00 & 3.00 & 3.00 & 3.00 & 3 & VG \\
\hline Situation & 3.00 & 3.00 & 3.00 & 3.00 & 3.00 & 3.00 & 3.00 & 3.00 & 3.00 & 3.00 & 3.00 & 3 & VG \\
\hline Process/Product & 3.00 & 3.00 & 3.00 & 3.00 & 3.00 & 3.00 & 3.00 & 3.00 & 3.00 & 3.00 & 3.00 & 3 & VG \\
\hline Scoring & 3.00 & 3.00 & 3.00 & 3.00 & 3.00 & 3.00 & 3.00 & 3.00 & 3.00 & 3.00 & 3.00 & 3 & VG \\
\hline Generalization & 3.00 & 3.00 & 3.00 & 3.00 & 3.00 & 3.00 & 3.00 & 3.00 & 3.00 & 3.00 & 3.00 & 3 & VG \\
\hline Grand Mean Rating & 2.93 & 3.00 & 3.00 & 3.00 & 2.93 & 2.93 & 3.00 & 3.00 & 3.00 & 3.00 & 3.00 & 2.98 & VG \\
\hline Qualitative Rating & VG & VG & VG & VG & VG & VG & VG & VG & VG & VG & VG & VG & \\
\hline
\end{tabular}


Task 2 was given a mean rating of 3.0 (Very Good) on content by the three evaluators in simple and compound interest. They did not suggest modifying or revise the RLPBT. They commented that when the task was executed in the class, the students would have to anticipate that they were the bookkeepers or the accounting assistants who were doing their job. They also anticipated that students would actively participate in answering the given balance sheet as they imagine that they are in the real world of business offering loans to customers. With these features, if Task 2 was found by the three evaluators, their judgment on Task 2 on simple and compound interest was favorable.

Task 5 on simple and general annuity was also given a mean rating of 2.97 (Very Good). One evaluator gave the learning competency on the content ratings of 2.0. He suggested that the learning competency and learning outcome should be made three instead of two. The other two evaluators gave no recommendations on the Task. As a whole, the three evaluators found the Task acceptable to use 1 in the simple and general annuity.

Task 7 on simple and general annuity was also given a mean rating of 3.0 (Very good). The evaluators gave no recommendations on the Task. They said that students would indeed participate in the task because of the cellphone.

Stocks and Bond, Task 8 was rated a grand mean rating of 3.0 (Very Good), each item on the content was all rated Very Good. No further comments or suggestions were given.

Task 10 in business and consumer loan was also given a mean rating of 3.0 (Very Good) on content by the three evaluators. They did not suggest modifying or revising the task. They commented that when the task was executed in the class, the student's excitement was seen on how the principal and the interest diminish every month. They also anticipated that the students would actively answer the given balance sheet as they imagine they are the lenders. Hey said that the content of Task 10 could cater to all types of learners. With these features of Task 10 found by the three evaluators, their judgment on the use of Task 10 on business and consumer loans was favorable.

Overall, the three evaluators' rating on the eleven performance-based tasks was indicative of excellent quality. The design and content of the RLPBTs satisfied the performance criteria of authentic assessments. The five ingredients of performance task in GRASPS form cited by [8] assured authentic transfer; gave the student a goal, a role, an audience, a setting, performance/product demands, and a set of standards and criteria by which work will be judged. These ingredients were manifested in the developed RLPBTs. As some studies show, teacher's assessment practices had significant relationships to classroom performance [3]. Effective practices in mathematics through its assessment plans were identified and its positive impact on teaching and learning [5].

\subsubsection{Assessment of the Instructional Use}

1) Assessment of the instructional use by the mathematics teachers

Nine Mathematics teachers assessed the content and execution of the eleven 
RLPBTs on simple and compound interest, simple and general annuity, stocks and bonds, and business and consumer loans based on their different components. All nine teachers said that the introduction of the PTs was clearly stated. They said the content of the Introduction drew and aroused the attention and interest of the students. The teacher finds the Introduction interesting to read. The teachers also remarked that the inclusion of a picture in the Introduction helped the learner focus their attention on the task correctly, which is an innovation in preparing performance tasks.

The nine mathematics teachers also said that the eleven PTs' learning competency explained the main intent/s of the PTs. They attested that the learning competencies were observable since the noun phrase used led to a well-defined product of the action implied by the phrase. In general, the teacher said that the competencies of the PTs were well-written and sequentially appropriate.

The nine mathematics teachers also said that the eleven PTs' learning outcomes explains the outcome of the PTs. They commented that the learning competency clearly described the expected learning outcomes. They attested that each learning outcome was observable since it led to a well-defined product or process. In general, the teacher said that the learning outcome described the process of the PTs.

In the task proper, the teachers said that in each PT, the GRASP explained the provision to be performed. Two mathematics teachers recommended that the number of roles and audience increased from two to four or five, depending on the number of students. Four to five members of the group will maximize the use of allotted time in PT 1 and PT 4. They added that the periods should be seen in PT 4 and PT 7 and the name of companies in PT 9. If Grasp would be correctly followed, the different steps to be executed would indeed be participated in actively by the students. They said that the students enjoyed the task than the usual paper and pencil assessment.

In the eleven PTs scoring component, two teachers recommended an additional point in the enumerated companies in PT 8. The nine teachers all agreed that the scores are appropriate in each task, and the level of performance are evident in each criterion in the analytic rubric used. The given scores in scoring may serve as measures to determine whether the learning competency and outcome were attained or not.

According to nine mathematics teachers, the provision of a generalization in the PTs served as a summary of the lesson. They all agreed that the guide questions formulated are of different levels of difficulty, and the discussion of these would certainly clarify the learner's thoughts. They said that if the students answered the questions correctly, they could summarize the lesson in their own words.

In totality, the developed RLPBTs were assessed favorably by nine mathematics teachers. They all agreed that the development and use of performance-based tasks in teaching business mathematics is an innovative move to maximize 
learning outcomes in mathematics.

2) Assessment of Instructional Use by the Students

The students' assessment on the eleven RLPBTs was described in terms of what they thought and felt about their instructional use.

- PT on Simple and Compound Interests

Nineteen out of twenty (95\%) randomly chosen Grade 11 mathematics students said that they loved PT 1; they found it enjoyable and challenging because they love to act. One student (5\%) said that the role-play was hard for her because she did not like to act. The same number of students, 19 out of twenty, chose Performance Task 1 rather than the usual activity because it was a challenge for them to act and compute simultaneously. One student chose the usual activity because she likes to solve the problem than to act in a play.

- PT 2 on Simple and Compound Interest

Twenty students (100\%) said that PT 2 was enjoyable and interesting; one student said it also gave her knowledge in lending or borrowing money that she might use someday when she has her own capital. Nineteen out of twenty (95\%) students chose the performance task rather than the usual activity because it was easy to follow and enjoyable. One student (5\%) chose both because he loves to compute different problems in mathematics.

- PT 3 on Simple and Compound Interests

Twenty (100\%) said that PT 3 was enjoyable; three out of twenty (15\%) said it was complicated at first because they were asked to identify and modify the mistakes in the given balance sheet. Nineteen (95\%) out of twenty students chose the performance task because it will help them analyze mistakes and one student (5\%) chose both the performance task and the usual activity.

- PT 4 on Simple and General Annuity

Twenty students (100\%) said that PT 4 was entertaining, enjoyable, and challenging. This task would help them because they would experience this task in the future. It gave them a realization of what they would ask for in an appliance center, especially the computation of prices. The same students (100\%) also chose this performance task rather than the usual activity because they acted and computed simultaneously, and they anticipated that they would encounter this situation someday.

- PT 5 on Simple and General Annuity

Twenty students (100\%) liked the PT 5 because it was easy and enjoyable, they have had the chance to create a leaflet, give their price and name of their own company. They imagined themselves as future entrepreneurs selling their own products and creating their own leaflet of advertisement. The same students chose the performance task rather than the usual activity because they enjoyed and imagined themselves as future entrepreneurs.

- PT 6 on Simple and General Annuity

Twenty students (100\%) said that PT 5 was interesting. All of the students wanted to have their own car someday, whether in installment or cash. They 
found this performance task interesting because it gave them the knowledge that the longer-term they apply, the higher interest would be applied. They also chose the performance task because it was challenging, engaging and did not feel they solve problems because they imagined themselves as salesman or buyer of the car.

- PT 7 on Simple and General Annuity

Twenty students (100\%) liked the PT 7 because it was easy and enjoyable; they cut and pasted different cellphones and create a streamer. They imagined themselves as future entrepreneurs selling their own products and creating their own advertisements. The same students chose the performance task rather than the usual activity because it would enhance their skills.

- PT 8 on Stocks and Bonds

Seventeen (85\%) out of twenty students said it was easy and enjoyable because they would choose the company in the newspaper; three students (15\%) said it was complicated because of its font size. Sixteen students (80\%) chose the performance task than the usual activity in the class because in the latter, they had a chance to know the Philippines' biggest companies. Four students chose the usual activity because it was tedious for them to look for the different companies because of its font size.

- PT 9 on Stocks and Bonds

Twenty students (100\%) said that PT 9 was easy and interesting. They find this task interesting because they would choose five different companies to invest in, easy because they would earn commission on every investment they would sell. Some students chose the performance task than the usual activity because they imagined that they socialize to sell stocks, and for them, it was easy compared to the other tasks.

- PT 10 on Business and Consumer Loans

Twenty students (100\%) said that PT 10 was challenging for them. They were challenged to know that the higher the principal when you apply for a loan, the higher interest it has. They were also challenged to get the zero outstanding principal at the end of the amortization period. Seventeen students (85\%) chose the performance task because they enjoyed doing the task, and they are interested in how the principal and interest diminish every month. Three students (15\%) chose both because they love computation.

\section{- PT 11 on Business and Consumer Loans}

Twenty students (100\%) said that PT 11 was interesting because they could differentiate a new loan and a renewed loan. The same students (100\%) chose the performance task because they learned more in this task, and they anticipated themselves applying for a loan in the future, or they could give suggestions to their parents when they apply for a loan.

The students' expressions of excitement and imagination are manifestations of the instructional benefits of the performance-based tasks in the study of concepts and operations in business mathematics. The findings of the study are 
supported by the idea of [21], that when the teachers design and implement innovative teaching methods in their classrooms, they are likely to capture the study's findings optimize their learning outcomes. Performance-based tasks are rarely done in most mathematics classes. When students had this experience, they find excitement and become more imaginative of what they will do and become when they are in the real world while learning. Zimmarro, as cited by [22], enumerated steps in the development of performance-based assessments where [23] suggested questions to get started on the activity which would present the learner an observable product, process, or the combination of both process and product.

\section{Conclusions and Recommendations}

From the findings of the study, it is concluded that the development of instructional materials like real-life performance-based tasks in Business Mathematics is made possible using the ADDIE Model. Also, the quality of developed instructional materials like RLPBTs is established by a defined process assessment.

In view of the study's findings and the conclusions drawn, it is recommended that a model in the development of activities must be chosen carefully to come up with the desired output. Also, it is recommended that performance-based tasks in other areas in mathematics be developed. The replication of the implementation of the developed RLPBTs in other Grade 11 mathematics classes to further establish validity and reliability of outcomes is also encouraged. Lastly, to encourage other researchers to conduct further research studies on the effectiveness of performance-based tasks on improving students' achievement and affective behavior.

\section{Conflicts of Interest}

The authors declare no conflicts of interest regarding the publication of this paper.

\section{References}

[1] Galman, S. (2019) On Solving Mathematical Problems the Spatial-Visual Ways. Journal of Applied Mathematics and Physics, 7, 559-566. https://doi.org/10.4236/jamp.2019.73041

[2] Lucas, M. (2012) Facilitating Learning. Lorimar Publishing House.

[3] Rodriguez, M. (2010) The Role of Classroom Assessment in Student Performance on TIMSS. Applied Measurement in Education, 17, 1-24. https://doi.org/10.1207/s15324818ame1701_1

[4] Mathematics Congress (2011) Things That Are Good: A Problem-Based Learning Approach in Mathematics.

[5] Callingham, R. (2010) Mathematics Assessment in Primary Classrooms: Making it Count. Research Conference 2010.

[6] Borko, H., Mayfield, V., Marion, S., Flexer, R. and Cumbo, K. (1997) Teachers' Developing Ideas and Practices about Mathematics Performance Assessment: Suc- 
cesses, Stumbling Blocks, and Implications for Professional Development. Teaching and Teacher Education, 13, 259-278. https://doi.org/10.1016/S0742-051X(96)00024-8

[7] Richey, R. and Klein, D. (2005) Developmental Research Methods: Creating Knowledge from Instructional Design and Development Practice. Journal of Computing in Higher Education, 6, 23-38. https://doi.org/10.1007/BF02961473

[8] Forest, E. (2014) The ADDIE Model: Instructional Design. Educational Technology.

[9] Wiggins, G.P. and McTighe, J. (2005) Understanding by Design. 2nd Edition, Pearson Education, Inc., Upper Saddle River.

[10] Martin, F. (2011) Instructional Design and the Importance of Instructional Alignment. Community College of Research and Practice, 35, 955-992. https://doi.org/10.1080/10668920802466483

[11] Paterson, C. (2003) Bringing ADDIE to Life: Instructional Design at Its Best. Journal of Educational Multimedia and Hypermedia, 12, 227-241.

[12] Manallack, D.T. and Yuriev, E. (2016) Ten Simple Rules for Developing a MOOC. PLoS Computational Biology, 12, e1005061. https://doi.org/10.1371/journal.pcbi.1005061

[13] Seeletso, M.K. (2015) The Design and Development of Instructional Materials as Potential Contributor to Academic Success of Secondary School Open and Distance Learners in Botswana. PhD. Thesis, University of Pretoria, Pretoria.

[14] Yousuf, M.I., Anwar, M.N. and Sarwar, M. (2008) Perceptions of Course Coordinators and Course Writers for Developing Distance Learning Materials. Turkish Online Journal of Distance Education, 9, 123-127

[15] Alzaghibi, M.A. (2010) Instructional Design: Development, Implementation and Evaluation of a Teaching Sequence Abut Plant Nutrition in Saudi. University of Leeds, Leeds.

[16] Seeletso, M.K. (2011) The Structure of ODL Study Materials. Francistown.

[17] Rowan, B., Correnti, R., Miller, R. and Cambun, E. (2009) School Improvement by Design: Lessons from a Study of Comprehensive School Reform Programs. In: Sykes, G., Schneider, B. and Plank, D.N., Eds., Handbook on Education Policy Research, Routledge, New York, 637-650. https://doi.org/10.12698/cpre.2009.sii

[18] Leach, J. (2005) Contested Territory: The Actual and Potential Impact of Research on Teaching and Learning Science on Students' Learning. In: Pinto, R. and Couso, D., Eds., Contributions from Science Education Research, Springer-Verlag, Dordrecht, 39-57. https://doi.org/10.1007/978-1-4020-5032-9_4

[19] Confrey, J. (2006) The Evolution of Design Studies as Methodology. In. R.K. Sawyer (Ed.). The Cambridge Handbook of the Learning Sciences, Cambridge University Press, New York, 135-152. https://doi.org/10.1017/CBO9780511816833.010

[20] Collins, A., Joseph, D. and Bielaczyc, K. (2004) Design Research: Theoretical and Methodological Issues. Journal of the Learning Sciences, 13, 15-42. https://doi.org/10.1207/s15327809j1s1301_2

[21] Imms, W., Cleveland, B. and Fisher, K. (2016) Evaluating Learning Environments. SensePublishers, Rotterdam. https://link.springer.com/book

[22] Gabuyo, Y. and Dy, G. (2013) Assessment of Learning II. Rex Bookstrore, Manila.

[23] Kubiszyn, T. and Borich, G. (2016) Educational Testing and Measurement. 11th Edition, Wiley, Hoboken. 